\title{
DIFFERENTIAL THERMAL ANALYSIS \\ OF THE GLASSY SYSTEM AsSe-AsTe
}

\author{
M.B. El-Den and M.K. El-Mously \\ Physics Department, Faculty of Science, \\ Ain Shams University, Cairo, Egypt.
}

\section{Abstract:}

Thermal induced phase transformation for the system AsSeAsTe have been studied using DTA. The dependence of the characteristic temperatures $\mathrm{Tg}, \mathrm{Tc}$ and $\mathrm{Tm}$ on the ratio of $\mathrm{Se} / \mathrm{Te}$ have been determined. The increase of Te content leads to the decrease of both $\mathrm{Tg}$ and $\mathrm{Tc}$ which means thetellurium inhances the crystallization process in these glasses exactly as in the case of $A s \mathrm{Se}_{3 / 2-x} \mathrm{Te}_{x}$ and $A_{5 S e_{5 / 2-x}} T e_{x}$. The kinetic calculations have been tried also. Reseanable results have been obtained for two compositions only AsSe $_{0.5} \mathrm{Te}_{0.5}$ and AsSe 0.1 Te 0.9 with $E_{\text {cryst. }}$ equal $31.0 \mathrm{~K} . \mathrm{cal} / \mathrm{mole}$ for the first and 45 and $65 \mathrm{~K} . \mathrm{cal} / \mathrm{mole}$ for the second. The other compositions either do not crystallize completely or have complicated and overlaped peaks.

\section{Introduction}

The binary system As-5e and the ternary system As-Se-Te have interesting properties as well as technological applications specially because they form wide range of glassy regiona. In the binary system As-Se the stiochemical compournd $\mathrm{As}_{2} \mathrm{Se}_{3}$ can be easily cotained in glassy state and can be easily traraformed to crystalline state. Also As5e can he ohtrained in both amorphous and crystalline states as indicated by their phase diagram (1). The other concentrations have eutitic character end it is difficult to crystallize. In the sytem As-Te there is only one stiocivernical compound $\mathrm{As}_{2} \mathrm{Te}_{3}$. All the other concentrations give mixed ctystalles atound eutitic points (1). Previously the etystallization kinetic have been studied for both systerns $A_{3} \mathrm{Se}_{5}-\mathrm{As}_{2} \mathrm{Te}$, and $A_{3_{2}} \mathrm{Se}_{3}-\mathrm{A}_{2} \mathrm{Se}_{3}-\mathrm{A}_{2} \mathrm{Te}_{3}$. $(2,3)$. While the system $\mathrm{A}_{3} \mathrm{Se}_{3}-\mathrm{As}_{2} \mathrm{Tr}_{3}$ can give limited solid solutions of both Asse $3 / 2 \& A_{5} T_{3 / 2}$ and crystallization tendency depending on the ratio Se/Te. The system AsSe-AsTe upon crystallization must give salid solutions with phase separation according to the phase diagram (4).

The ptesent work deals with the same study applied to AsSc-AsTe in a trial to study the crystallization kinetics using OTA. The $\mathrm{X}-t$ - ay study (5) indicates the presence at least two phases. Their concentrations depends on the ratio of $5 e$ to Te. These phases may be AsSe with Te replacing So and AsTe with Se teplacing Te. The kinetic calculation, may help in understanding the physicel phenorvura ussociated with the crystallization process. 



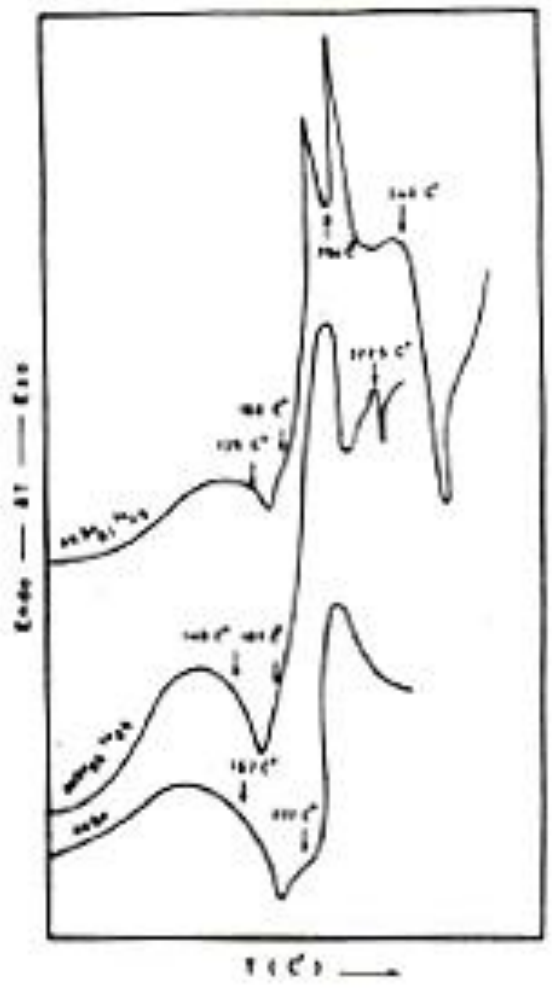

Fiq.1: DrA Thetmograms for the compositions AsSe, AsSe ${ }_{0.5} \mathrm{Te}_{0.5}$ and $\mathrm{AsSe}_{0.1} \mathrm{Te}_{0.9}$

Table(1) Charecteristic temperature $(6)=10 \mathrm{deq} / \mathrm{min})$ of Asse, $\mathrm{Te}_{\mathrm{x}}$ glasses. The temperature are given in ${ }^{\circ} \mathrm{C}$

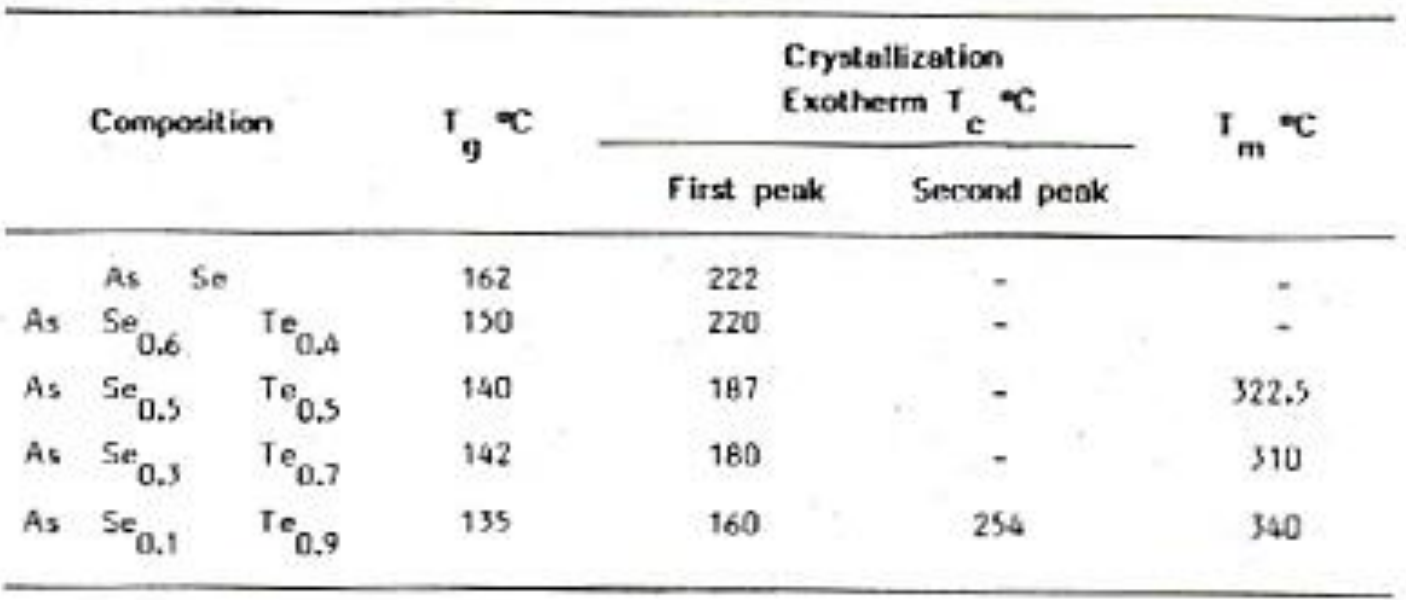





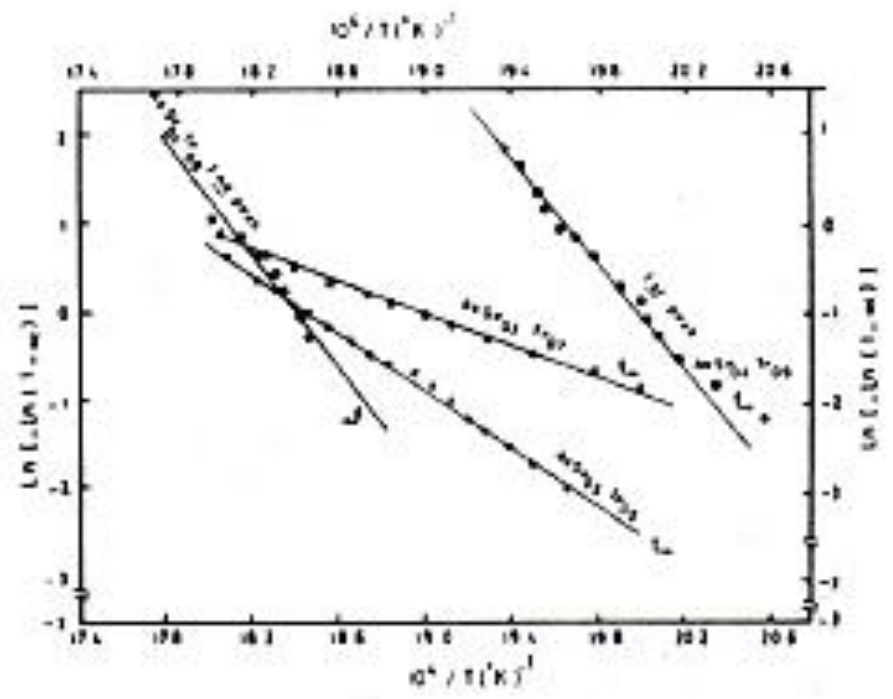

Fign2: Plats of In [-In (1-) )] versus 1/T for the first and second peok for the compositions AsSe ${ }_{0.5} \mathrm{Te}_{0.5^{+}} \mathrm{AsSe}_{0.3} \mathrm{Te}_{0.7}$ and AsSe $0 . \mathrm{Te}_{0.9}$

Tuble(2): Crystallization kinetic parameters of AsSe, ${ }_{1-x} \mathrm{Te}_{x}$ glasses.

\begin{tabular}{|c|c|c|c|c|c|c|}
\hline \multicolumn{3}{|c|}{ Composition } & \multicolumn{2}{|c|}{ Fitst Peak } & \multicolumn{2}{|c|}{ Second Peak } \\
\hline & & & $\mathbf{n}$ & E.Keal/mol & n & E. $\mathrm{Kcal} / \mathrm{mol}$ \\
\hline & As & Se & $2 \Omega$ & 27.0 & - & - \\
\hline As & 5 & $T_{0.4}$ & 2,4 & 28.0 & - & - \\
\hline As & $\mathrm{Se}_{0.5}$ & Te. 0.5 & 2.8 & 310 & - & - \\
\hline As & $\mathrm{Se}_{\mathrm{D} .5}$ & $\mathrm{Te}_{0.7}$ & 2.4 & 17.0 & - & - \\
\hline As & ${ }_{0,1}$ & $T e_{0.9}$ & 2.8 & 45.0 & 3.8 & 650 \\
\hline
\end{tabular}



values of " $N$ " (2.0-2.8) which defined the details of nucleation arnd crystal growth according to equation (4) indiestes two of three dimensional growth of crystalline phase.

\section{Conclusions}

1. The DIA thermograms fot the system AsSe $1-\mathrm{x}_{\mathrm{x}} \mathrm{w}$ with $0<x<0.5$ do not show crystallization for the tate $10 \mathrm{deg} / \mathrm{min}$.

2. Under the same ecenditions for the tange of concontrations $0.5 \leqslant x \leqslant 1$ thete is one of two crystallization peaks indicating the possibility of the presence of two etystolline phases.

3. The compoxition AsS $\mathrm{r}_{0.5} \mathrm{Tr}_{0.5}$ corresponds to the minimum microheterogenity with the least activation energy of ctystallizaticn

4. Within these systems the crystallization process takes place in two of thee dimension with $2<n<28$.

\section{References:}

1. SA. Demborskil and N.P. Lustrunya, Zh Neotgan Khim, 9, 660-664, (Russ). J. Inatg Chem. 9, 36ㄱ-367, (1964).

2. MF. Koxkata and MB. E1-Den, International Centet for Theofetical Physice, Irieste, Italy, K/C3/99.

3. MB. EI-Den and MK. EI-Mously, International Centre for Theoretical Physics, Trieste, It aly, IC/85/156.

4. A.S. Khroskenka, S.A. Dombovikil and N.P. Lugnaya, I. Inetg. Chem, 15, 1705, (1970) (Russian).

5. MF. Kotkata, AM. Shamah, MB. EI-Den and MK. El-Moxialy, Acto Phys. Hung. 54, 47. (1983).

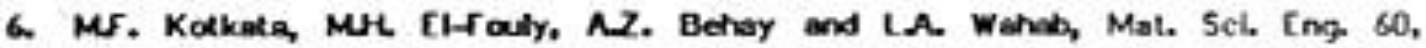
$163(1983)$.

7. Otrateor and Orlove Inorgan Materisl 7, 2166, (1971) (Russian).

B. M. Arrarni, D, Chem, Physa, 8, 212 (1940).

2. F. P. Piloyan, LO. Ryabchiken and OS. Novikova, Nature, 212, 1229, (1966).

10. H.l. Borchard, J. Inorg. Nucl. Choms 12, 252 (1960).

11. Mr. Kotkata arod E.A. Mahnoud, Mot. Sti., Enq 34, 163 (1982).

12. Hh. Sharp, G.V. Btindty and BN. Achar, J. Am. Ceram. Soc. 49, 979 (1966). 